\title{
SINESTESIA E O TRANSTORNO DO ESPECTRO DO AUTISMO (TEA)
}

\author{
SYNESTHESIA AND THE AUTISM SPECTRUM DISORDER (ASD)
}

\section{Maria Cecilia Tomasia , Jaciara Muller Brandes ${ }^{b}$, Juliana Lopes ${ }^{c}$, Henrique Sartori Klostermann', Luiz Arthur Rangel Cyrino ${ }^{\mathrm{e}}$}

\author{
aceciliatomasi10@hotmail.com, bjaciaramuller96@gmail.com, cjuliana.egf@gmail.com, dhenrique.sartori49@gmail.com, erangel7@uol.com.br \\ Universidade da Região de Joinville - Joinville (SC), Brasil
}

Data de recebimento do artigo: 23/08/2017 Data de aceite do artigo: 19/09/2017

\section{RESUMO}

Introdução: A sinestesia, que possui uma prevalência de 4\%, é uma condição neurológica em que um único estímulo elicia experiências adicionais a outro sentido sensorial, que pode ser: visual, auditivo, olfativo, gustativo e tátil. Essa condição não está incluída no Manual Diagnóstico e Estatístico de Transtornos Mentais $5^{a}$ edição (DSM-5), entretanto suas bases neurológicas podem estar atreladas a algumas disfunçôes comportamentais presentes em outros transtornos, como no transtorno do espectro do autismo (TEA). Objetivo: Realizar uma revisão de literatura sobre a sinestesia e sua possível correlação com o TEA. Materiais e métodos: $\mathrm{O}$ levantamento bibliográfico foi feito por meio de consultas às bases de dados eletrônicas PubMed, ScienceDirect, SciELO, Google Acadêmico e ResearchGate, sendo incluídos artigos e livros publicados nas línguas portuguesa e inglesa, entre os anos 1995 e 2015, que documentassem sobre a sinestesia e o TEA. Resultados: Para compor esta revisão, 37 artigos e 4 livros, nacionais e internacionais, foram incluídos. Os estudos mostraram que a prevalência da sinestesia é maior em indivíduos autistas. Outros resultados apontam semelhanças nas bases neurológicas e genéticas envolvidas no TEA e na sinestesia, que explicam o processamento perceptual sensorial alterado em ambos. Conclusão: Com base em diferentes estudos, conclui-se que a sinestesia e o TEA podem apresentar uma correlação e que seus aspectos apontam um desafio para futuras pesquisas.

Palavras-chave: Sinestesia; percepção; autismo; psicologia; neurologia.

\section{ABSTRACT}

Introduction: Synesthesia, which has a prevalence of $4 \%$, is a neurological condition in which a single stimulus elicits additional experiences from another sensory sense, which can be: visual, auditory, olfactory, gustatory and tactile. This condition is not included in the DSM-5, however, its neurological bases may be linked to some behavioral disorders present in other disorders, such as Autism Spectrum Disorder (ASD). Objective: To perform a literature review on synesthesia and its possible correlation with ASD. Materials and methods: A bibliographic survey was carried out through the electronic databases: PubMed, Science Direct, SciELO, Google Academic and Research Gate, including articles and books, published in Portuguese and English. Between 1995 and 2015, to document synaesthesia and ASD. Results: To compose the present review, 37 articles and 4 books, national and international were included. Studies have shown that the prevalence of synesthesia is higher in autistic individuals. Other results point to similarities in the neurological and genetic bases involved in ASD and synesthesia, which explain altered sensorial perceptual processing in both. Conclusion: In this article, therefore, it was seen through different studies that synesthesia and TEA may present a correlation and that its aspects present a challenge for future research.

Keywords: Synesthesia; perception; autism; psychology; neurology. 


\section{Introdução}

Sinestesia é uma condição neurológica cuja prevalência é estimada em torno de $4 \%$ na população, conforme um dos recentes estudos realizados, que teve como amostra 500 participantes das Universidades de Edinburgh e Glasgow, na Escócia ${ }^{1}$. Nessa condição, um único estímulo sensorial desencadeia experiências adicionais a determinado sentido, fenômeno ocorrido por meio da combinação dos sentidos sensoriais (visão, audição, olfato, paladar e tato $)^{2,3}$. O estímulo que elicia a experiência é chamado de indutor, e as sensações adicionais são ditas concorrentes ${ }^{4}$. As experiências adicionais, na sinestesia, frequentemente ocorrem entre sistemas que desencadeiam a sensaçáo, como ver cores ao escutar um som ou sentir texturas ao degustar determinado alimento ${ }^{2}$. Nessa condição, as sensações ocorrem simultaneamente, ou seja, não há substituição de uma por outra, mas sim uma adição ${ }^{3}$. Existem várias formas de sinestesia; a mais comum e mais bem estudada é a do tipo grafema-cor, em que a visão de letras ou números elicia a experiência visual de cores específicas nos grafemas ${ }^{2}$.

Um dos pioneiros a explorar o assunto foi Francis Galton, que publicou, em 1880, um artigo na revista Nature sobre casos de sinestesia e sua hereditarieda$\mathrm{de}^{2,7}$. Porém o estudo da sinestesia, desde as pesquisas de Galton, foi visto como uma curiosidade nas áreas da Psicologia e da Neurociência ${ }^{2}$. O processo sinestésico poderia ser notado como decorrente do uso de drogas (LSD e mescalina, que produzem efeitos semelhantes). Mas a partir das descobertas sobre aspectos importantes do funcionamento cerebral humano, como o pensamento abstrato, a metáfora e a linguagem, contribuiu para os avanços na pesquisa sobre sinestesia ${ }^{8}$. Ainda assim, a presença de tal condição neurológica em indivíduos foi, por um período, relacionada às memórias da infância e suas associações - atribuiçôes de cores aos números e às letras - e às metáforas, o uso de cores ou adjetivos (brilhante, doce, escuro, entre outros) para sons musicais, por exemplo ${ }^{8,9}$.

Atualmente pesquisas apontam para processos cerebrais cognitivos, perceptivos e de sistemas neurais ${ }^{8}$. Diferentes hipóteses sobre a neurobiologia e os mecanismos cognitivos que envolvem a sinestesia coexistem, entre elas, destacam-se duas: a primeira baseia-se na afirmação de que há uma falha na poda sináptica em sinestetas, o que provocaria o agrupamento de sensaçóes; a segunda hipótese concentra-se na ideia de que há uma desinibição no processo de feedback que ocorre no cérebro, o que também causaria a experiência da $\operatorname{sinestesia}^{10-12}$. Diferenciações nas substâncias branca e negra é outro fator neurobiológico que explicaria a sinestesia ${ }^{5}$. Ademais, novas pesquisas apontam para dados genéticos envolvidos na sinestesia ${ }^{7}$ juntamente com a interação ambiental ${ }^{12}$.
A sinestesia possui características distintas de um processo de associação de memórias ${ }^{8}$. Por intermédio do estudo dessa condição, verificou-se que as experiências são consistentes, idiossincráticas, involuntárias e memoráveis ${ }^{5,13}$.

A consistência na sinestesia diz respeito às mesmas formas de associaçóes que persistem ${ }^{5}$. Assim, as sensaçôes eliciadas por determinado estímulo não se alteram com o tempo ${ }^{2}$, eo que é experimentado não é complexo, nem pictórico, e sim um conjunto de sensaçóes simples ${ }^{13}$.

A involuntariedade da experiência demonstra o não envolvimento do processo de decisão consciente ${ }^{2}$. Os fenômenos que se dão pela junção das informaçôes sensoriais evidenciam que a resposta é realmente automática, o que possibilita ao sinesteta ter uma percepçáo mais rápida do que os não sinestetas ${ }^{13}$.

A experiência na sinestesia é memorável, pois sinestetas possuem grande capacidade de memória, às vezes fotográficas. Os bits adicionais de informação provenientes da sinestesia fazem com que as tarefas triviais sejam carregadas de emoção ${ }^{13}$.

A sinestesia, embora seja uma condição neurológica, não está inserida no Manual Diagnóstico e Estatístico de Transtornos Mentais 5a edição (DSM-5) ${ }^{14}$, uma vez que normalmente não interfere na vida diária do sinesteta ${ }^{4,6}$ - exceçáo para os casos severos, nos quais as informaçóes sensoriais da sinestesia influenciam a vida normal ${ }^{7}$. Em contrapartida, as bases neurológicas nessa condição podem estar atreladas a algumas disfunçóes comportamentais presentes na dislexia, no transtorno de déficit de atenção (TDA) e no transtorno do espectro do autismo $(\mathrm{TEA})^{15,16}$. Além disso, em um recente mapeamento genético, regiōes de genes implicados na sinestesia foram vinculadas à epilepsia, dislexia e ao TEA ${ }^{7}$.

Especificamente, no TEA, a partir do diagnóstico realizado com base em uma díade de prejuízos (comunicação e interaçáo social e padrôes restritos de comportamento) ${ }^{14}$, pode-se adentrar nos processos sensoriais e perceptuais envolvidos nesse transtorno ${ }^{17}$. Assim, o autismo e a sinestesia são condiçôes diferentes que podem se concatenar, já que, quanto ao TEA, recentes estudos revelam diferenciaçōes nas conexóes neurais ${ }^{18} \mathrm{e}$ também há evidências de que o autismo esteja relacionado a um aparato sensorial com disfunçóes ${ }^{19}$. Por meio desses aspectos, portanto, pode-se pensar no autismo como um transtorno de natureza sensorial, para além dos seus critérios diagnósticos ${ }^{17}$.

Com base na literatura pesquisada sobre o tema e em virtude da carência de compreensão sobre a relação entre a sinestesia e o TEA, notou-se a importância de pesquisar, promover clareza e trazer à luz novas informações e perspectivas acerca desse tema. Considerando essa necessidade, este estudo tem o objetivo de fazer uma revisão de literatura sobre a sinestesia e sua possível correlaçáo com o TEA. 


\section{Desenvolvimento}

Este estudo refere uma revisão narrativa, desenvolvida com base na relação dos aspectos entre a condição neurológica da sinestesia e o TEA. A pesquisa foi realizada entre abril e dezembro de 2016, com base em um levantamento bibliográfico mediante consulta às seguintes bases de dados eletrônicas: Medical Literature Analysis and Retrieval System Online (Medline/ PubMed), ScienceDirect, Scientific Electronic Library Online (SciELO), Google Acadêmico e ResearchGate. A estratégia de busca consistiu na utilização dos seguintes descritores: "autismo", "TEA", "sinestesia", de forma isolada e, posteriormente, com suas combinaçóes. Incluíram-se artigos e livros completos, publicados nos idiomas português e inglês, com delimitação de período de publicação de 2000 a 2015 (com exceção de dois artigos, ambos publicados em 1995), que registrassem sobre sinestesia, TEA e a possível correlação entre ambos. Os artigos identificados foram analisados inicialmente pelo título e resumo e, subsequentemente, por sua leitura na íntegra. Após a exclusão dos escritos que não obedeciam aos critérios de inclusão, foram agregados a esta revisão 37 artigos e 4 livros, sendo 29 internacionais e 12 nacionais.

\section{Bases neurais da sinestesia}

O conhecimento da sinestesia existe há muito tempo, mas recentemente, por meio de novas investigaçôes científicas, iniciou-se a descoberta de sua base neurológica. Em vez de ser uma anomalia, ela pode oferecer insights benéficos sobre a base da percepção, como um processo comum ${ }^{20}$. A sinestesia se dá por uma estimulação de um sistema sensorial que leva as experiências associadas a um segundo sistema não estimulado. Embora seja muitas vezes referida como uma condição neurológica, não está listada no DSM-5 ou nas categorias da Classificação Estatística Internacional de Doenças e Problemas Relacionados com a Saúde (CID). Dada a falta de compreensão do assunto, tanto para os indivíduos com sinestesia quanto para os clínicos, uma visão mais ampla dos mecanismos neurais desse fenômeno é claramente desejável .

Existem duas teorias predominantes acerca do substrato neural da sinestesia, e ambas estão enraizadas em processos de desenvolvimento neural ${ }^{12}$. A primeira está centrada na discussão de que a sinestesia possa ocorrer pela poda sináptica neural incompleta, em áreas cerebrais adjacentes; a segunda teoria sugere que essa condiçáo ocorre por um processo de falha na inibição do feedback de áreas corticais superiores para áreas sensoriais primárias ${ }^{2,4,9,12}$. Em ambas as teorias, o desenvolvimento envolve a proliferação de conexôes entre áreas sensoriais corticais e, em seguida, a especialização de cada área sensorial para uma modalidade sensorial particular. A especialização é impulsionada pela experiência, que influencia quais conexóes serão podadas, moldando a reentrada do feedback ${ }^{12}$. Ainda em paralelo, são propostas hipóteses, nomeadas de "ativação cruzada local", "feedback desinibido de longo alcance", "processamento reentrante", pois é fundamental ter em mente que um único modelo pode não conseguir captar a variabilidade nas experiências sinestésicas. Os mecanismos neurais podem ter tanto um fator em comum, presente em todos os tipos de sinestesia, quanto fatores individuais e variáveis, gerando experiências particulares ${ }^{2,4}$.

\section{Poda sináptica incompleta ou ativação cru- zada (cross-activation)}

Existe teoria de que temos muitas conexóes ao nascer e que estas são reduzidas durante a infância, restando apenas as ligações funcionais necessárias e mais eficien$\operatorname{tes}^{2,12}$. Dado que a sinestesia possui um fator de hereditariedade, essa teoria sugere que genes podem levar a uma falha de poda sináptica, de forma que as regióes adjacentes do cérebro no giro fusiforme permaneçam conectadas, mesmo em adultos, levando a ativaçáo cruzada entre tais regióes ${ }^{11}$. Ao final do desenvolvimento cerebral, cada área cortical sensorial se especializa no processamento de informaçóes sensoriais específicas o córtex auditivo responde à entrada de um estímulo sonoro nos ouvidos, por exemplo. Assim, essa teoria baseia-se no fato de que as áreas corticais sensoriais não sejam, no cérebro prematuro, tão especializadas como elas se tornam no cérebro adulto. Em vez disso, existem ligações temporárias entre áreas corticais sensoriais que são podadas durante a infância e dependentes da experiência ${ }^{12}$. Sendo assim, há uma concordância sobre uma superabundância de conexôes entre áreas corticais sensoriais na primeira infância e que a poda é dependente da experiência; assim, a ativação cruzada seria preexistente $^{2,12,21}$. A teoria de sinestesia neonatal afirma que, até cerca de 4 meses de idade, as crianças experimentam estímulos sensoriais em um caminho indiferenciado, por exemplo, o fato dos sons poderem resultar em sensaçóes auditivas, visuais e táteis. Mais tarde, com o desenvolvimento padrão dos sentidos, os estímulos sensoriais diferenciam-se, e o processamento sensorial torna-se específico. Logo, a sinestesia ocorre quando essa diferenciação é incompleta, deixando associaçōes cruzadas entre dois ou mais sentidos ${ }^{22,23}$. Essa teoria, ainda, pode prover insights sobre um novo mecanismo para a formação das conexôes neurais ${ }^{21}$. 


\section{Feedback desinibido (disinhibited feedback)}

A explicação alternativa de sinestesia baseia-se no processo de feedback desinibido de áreas corticais superiores (associativas) para as áreas corticais sensoriais inferiores (primárias) ${ }^{12}$. O córtex é organizado em estruturas hierárquicas, ou seja, estruturas de processamento mais simples enviam sinais para estruturas mais complexas até os sinais chegarem a áreas de integração em vias sensoriais. Há também ligaçóes na direção oposta, que enviam sinais de retorno para as áreas primárias, reforçando a percepção da sensação estimulada, enquanto a percepção de outros estímulos inconsistentes com o estímulo é inibida, a fim de evitar experiências sinestésicas em adultos normais ${ }^{4,9}$. Na sinestesia alguns desses mecanismos de feedback inibitórios falham, permitindo que áreas sensoriais primárias passem a ser ativadas por um estímulo derivado de uma área sensorial distinta ${ }^{12,24}$.

\section{Genética na sinestesia}

A condição neurológica da sinestesia possui uma hereditariedade ${ }^{13,15}$, o que pode explicar a prevalência relativamente alta da condiçáa $(4 \%)^{25}$. Nota-se que por volta de $40 \%$ dos sinestetas relatam, pelo menos, outro membro da família com sinestesia ${ }^{23,25}$. Além disso, a maior incidência dos casos de sinestesia em família envolve somente uma forma, ao passo que um menor número apresenta membros familiares com tipos distintos de agrupamento sensorial ${ }^{25}$.

$\mathrm{Na}$ sinestesia há um desequilíbrio de predomínio entre os sexos. $\mathrm{Na}$ maior parte das pesquisas realizadas há um número maior de casos em mulheres do que em homens ${ }^{25}$. Dessa maneira, a transmissão, em hipótese, pode estar atrelada à genética ligada ao cromossomo $\mathrm{X}$, visto que a maior existência dos casos parte de mãe para filha e, ademais, não há registros sobre casos de pai para filho ${ }^{15,22,26}$.

O desenvolvimento neuronal pode ser considerado em diferentes aspectos - sinaptogênese, eliminação de sinapses excedentes e apoptose celular. Na sinestesia há uma diferenciação nos padrôes das conexôes neurais. Assim, a genética pode estar envolvida na sinaptogênese e na apoptose, já que a eliminação sináptica é realizada através dos estímulos ambientais ${ }^{26,27}$.

A relação da sinestesia com diferentes genes pode explicar diversos aspectos de tal condição. As análises genéticas revelam linkage em regiōes dos cromossomos 2 e 6 - no cromossomo 6, especificamente, o envolvimento da região que possui lócus EPHA7, o qual está envolvido em aspectos do desenvolvimento cerebral como apoptose e formação das conexões neurais corticais, pode se mostrar uma das explicações para a sinestesia ${ }^{7,27}$. Além disso, em um mapeamento realizado na sinestesia visual-auditiva, observou-se linkage nos cromossomos 2q, 5q, 6q e 12p, e não houve confirmação de linkage no cromossomo X. O cromossomo 12 contém o receptor NMDA, que desempenha um papel importante para o aprendizado e a memória; já no cromossomo 5, o gene DPYSL3 foi identificado nas análises, sendo este importante para o crescimento e orientação axonal. Esses dados revelam que a genética na sinestesia é complexa, envolvendo variados modos da herança para diferentes genes ${ }^{7}$.

Com base nas diferenças individuais nos casos que envolvem a sinestesia, pode-se compreendê-la dentro de um espectro, em que pouco se sabe das condiçōes e dos eventos que traduzem um genótipo em um fenótipo $^{25,26}$. Nesse sentido, para a sinestesia há a herança genética como uma tendência geral para alteraçôes do funcionamento cerebral padrão ${ }^{25}$.

\section{Transtorno do espectro do autismo (TEA)}

O TEA, que possui uma prevalência estimada em 1/88 neonato e um maior predomínio no sexo masculi$n^{28}$, é enquadrado dentro dos transtornos do neurodesenvolvimento - um grupo de condiçóes que tem início no período de desenvolvimento infantil, manifestando-se cedo durante a infância. Esse grupo de transtornos é caracterizado por déficits que acarretam prejuízos no funcionamento pessoal, social, acadêmico ou profissional ${ }^{14}$.

A etiologia no TEA ainda é desconhecida ou não comprovada ${ }^{28,29}$, entretanto, os critérios para diagnóstico são conhecidos. Para a avaliação desse transtorno do neurodesenvolvimento, os critérios diagnósticos estáo dispostos em uma díade. A primeira dimensão da díade está relacionada aos déficits constantes na interação social e na comunicação em diversos contextos. Assim, há déficits na reciprocidade socioemocional, nos comportamentos comunicativos e no desenvolvimento, estabilidade e compreensão dos relacionamentos. A segunda dimensão da díade refere-se aos padróes reservados de interesses, comportamento ou atividades - estereotipia das açóes motoras, do uso de objetos ou da fala; persistência nas mesmas coisas, aderência inflexível a rotinas ou convenções ritualizadas de desempenho verbal ou não verbal; interesses fixos e extremamente reservados; hipo ou hiper-reatividade a excitação sensorial ou interesse infrequente por aspectos sensoriais do ambiente ${ }^{14}$.

\section{Bases neurológicas no TEA}

Embora não se saiba ao certo as causas do TEA, a hipótese mais bem aceita no contexto científico é de que haja uma origem orgânica, que se relaciona com alteraçôes no desenvolvimento do sistema nervoso ${ }^{28-30}$. 
Assim, mecanismos neuronais estão presentes em vários estudos sobre o assunto. Na década de 1980, análises neuroanatômicas post-mortem em pessoas com autismo revelaram o comprometimento de várias áreas (lobo frontal e temporal, gânglios de base e tálamo) ${ }^{31}$. Vários estudos mostram prejuízos em regióes cerebrais, como a amígdala, o cerebelo, o hipocampo, o corpo caloso, os gânglios da base, bem como aumento dos ventrículos cerebrais $^{32}$. Ademais, também há implicaçóes nas conexốes entre o sistema límbico e o lobo frontal ${ }^{33}$.

A neuroimagem revelou alteraçôes que se relacionam a um prejuízo na ativação de áreas do córtex envolvidas no reconhecimento de faces, como o giro fusiforme ${ }^{33}$. $\mathrm{Na}$ região temporal, existem alteraçóes no sulco temporal superior, importante regiâo para a percepçáo dos estímulos sociais. Assim, no TEA, há uma hipoativação na percepção de faces e cognição social ${ }^{32}$.

O cerebelo é visto como uma das principais estruturas comprometidas no autismo ${ }^{18}$, em que há uma redução das células de Purkinje e das células glandulares na estrutura cerebelar; as células de Purkinje são relevantes, pois recebem o maior número de sinapses do sistema nervoso central (SNC) $28,30,32$. A hipoplasia no cerebelo pode ocorrer em virtude de uma perda dos neurônios durante a vida ou pode estar sujeito a uma produçáo e/ou migraçáo alterada das células já no período intrauterino ${ }^{30}$.

O comprometimento da amígdala e do tálamo aparece também nas bases neurológicas do TEA. A amígdala está ligada diretamente às emoçôes e à sociabilidade; o tálamo funciona como um mediador, retransmitindo aferências ao SNC ao recebê-las ${ }^{31,32}$.

As áreas cerebrais envolvidas em um circuito denominado cérebro social e os "neurônios espelho" são comprometidos no autismo ${ }^{32,33}$. Assim, no TEA há uma incapacidade de realizar atividades que se relacionem com a posse da teoria da Mente - dependente da empatia, ou seja, do funcionamento dos "neurônios espelho" para a imitação interna das atitudes e emoçóes dos outros ${ }^{34}$.

Outros aspectos das alteraçóes neuronais do TEA estáo comprometidos na fisiologia e morfologia cerebral - aumento do volume total do cérebro, modificação das conexóes neurais em decorrência de alteraçóes, tanto na eliminaçáo (poda sináptica ineficiente) quanto na formação das sinapses e na migração dos neurônios ${ }^{18,31}$. Assim, há aumento na espessura de várias áreas corticais, redução de sinapses no hipocampo, amígdala e cerebelo e aumento na concentração de serotonina no cérebro em geral ${ }^{29,32}$.

\section{Genética no TEA}

As causas neurobiológicas e os indícios para uma predisposição observada em gêmeos e famílias no TEA são um indicativo para uma base genética complexa, que se relaciona com muitos genes, cromossomos distintos e mutaçôes ${ }^{29,35}$, além da interação entre genética e ambiente ${ }^{18}$. Alteraçóes em diversos cromossomos podem estar atrelados ao TEA - existem evidências significantes para alteraçóes nos cromossomos 2q, 7q, 16p e 17q, além disso, pode haver uma ligaçáo com o cromossomo $\mathrm{X}$, percebida nas comorbidades dispostas no TEA ${ }^{29,36}$.

Os cromossomos $2 \mathrm{q}$ e $7 \mathrm{q}$ possuem um grande potencial para a explicação genética do TEA ${ }^{35}$. Em análises genéticas viu-se, com relevância, a implicação de dois genes localizados na região $2 \mathrm{q} 32$ e os genes $\alpha 1 \mathrm{CHIM} \mathrm{e}$ a2CHIM, que estão envolvidos com a diferenciação e sinaptogênese dos neurônios ${ }^{36}$. No cromossomo $7 \mathrm{q}$ foram encontradas diversas regióes com alteraçốes. Há um comprometimento do gene FOXP2, na regiáo 7q31.7, o qual é de suma importância para o desenvolvimento da linguagem $^{33,35}$; também foram verificados os genes presentes nas regiōes $7 \mathrm{q} 32$, que medeiam a orientaçâo axonal, e 7q22.7, os quais codificam a reelina (RELN), proteína que desempenha um papel importante para a migração neuronal ${ }^{35,36}$.

Os cromossomos 16p e 17q foram encontrados como possíveis marcadores para o TEA. Na regiáo 16p13.3, é encontrado o NMDA, um receptor que desempenha uma participação importante para a plasticidade cerebral. $\mathrm{Na}$ área $17 \mathrm{q} 11$, há o gene SLC6A4, que está envolvido na codificação do transportador para recaptação de serotonina. Dessa maneira, uma mutaçáo nesse gene causaria acúmulo do neurotransmissor ${ }^{35,36}$.

No cromossomo $\mathrm{X}$, a região $\mathrm{Xq} 9-\mathrm{q} 23$ possui o gene AGTR2 - a deleção deste pode estar associada aos déficits intelectuais, que são encontrados em casos no TEA -, e na regiâo Xq13-q21 há indicação para o comprometimento dos genes da família neuroliguinas, que podem ser importantes para o bom funcionamento das sinapses ${ }^{29}$. Além dessas alteraçôes, há uma relação entre o TEA e a síndrome do X-frágil ainda investigada; sabe-se que 30\% casos de X-frágil apresentam o TEA como comorbidade ${ }^{29,35}$.

As mutaçôes ocorridas em uma família de proteínas, a Shank, podem também estar atreladas às bases genéticas do TEA e à sua forte relação com a idade paterna - observa-se que isso está associado às mutações das células germinativas, o que pode influenciar outros processos similares. Mutaçóes no gene SHANK3, localizado no cromossomo 22q13.3, apontam para uma forte correlação com o TEA, já que esse gene codifica a proteína Shank3, que está diretamente relacionada à sinaptogênese, estabilidade das sinapses e dos receptores de glutamato e maturação dos espinhos dendríticos ${ }^{35}$.

\section{Correlação entre sinestesia e autismo}

Há evidências para uma ligação entre sinestesia e autismo nos dados relacionados à prevalência na população: 
a sinestesia ocorre em por volta de $4 \%$ da população; e o TEA, em 1\%, apresentando, portanto, uma correlação entre as condiçôes. Ademais, outras ligaçóes são observadas nas características neuronais, genéticas e sensoriais ${ }^{7,16,37}$.

Um estudo realizado mediante autorrelato - intermediado por um questionário, Synaesthesia Questionnaire, e pelos testes Autism Spectrum Quotient e The Test of Genuineness-Revised - com 172 indivíduos autistas e 123 indivíduos típicos mostrou que a presença de sinestesia é em torno de três vezes maior em indivíduos autistas. Acredita-se que o motivo da maior prevalência no grupo dos autistas do que no grupo controle ocorre pelo compartilhamento de fatores biológicos ${ }^{37}$. Em outro estudo, o objetivo foi mensurar a correlaçáo entre sinestesia grafema-cor em indivíduos com TEA, por intermédio de escalas de autoavaliação e testes: Autism Spectrum Quotient, Empathy Quotient, Synesthesia Test Battery e Likert Scale. Verificou-se, em uma amostra de 21 sinestetas e autistas, que a sinestesia grafema-cor estava presente em número significante. Além disso, outros tipos de sinestesia foram relatados, incluindo-se: som-toque, nota musical-cor, mês-cor, dor-cor, entre outras; o total de 36 tipos diferentes de sinestesia, além do tipo grafema-cor, foram ressaltados nos testes ${ }^{16}$.

Enquanto a sinestesia é caracterizada por uma adição de estímulos, com os quais se relacionam uma modificação da ativação cerebral em áreas sensoriais corticais, as mudanças no processamento sensorial e os sintomas sensoriais estão presentes no autismo ${ }^{7,16}$. Os sintomas sensoriais também parecem ser mais comuns no TEA do que em outros transtornos do desenvolvimento, haja vista que, das crianças com TEA, 96\% apresentam hiper e/ou hipossensibilidades em vários campos sensoriais ${ }^{20,38-40}$. Em um estudo realizado com o intuito de descrever alteraçôes sensoriais em um grupo de 208 crianças diagnosticadas com TEA, $76 \%$ da amostra apresentou pelo menos um tipo de alteração sensorial. Essas alterações foram, na maior parte dos indivíduos, hiperatividade ao estímulo sonoro e hipoatividade à dor ${ }^{39}$.

$\mathrm{O}$ autismo é definido primeiramente nos seus sintomas sociais, e sabe-se que as alteraçóes sensoriais podem estar correlacionadas com tais sintomas ${ }^{19}$. As características específicas desse transtorno do desenvolvimento, como seletividade na alimentação, problemas no sono e comportamento estereotipado, podem estar atreladas às modificaçóes sensoriais em indivíduos autistas ${ }^{39}$. Um exemplo disso pode ser notado nos déficits na linguagem, os quais são uma característica central do TEA. Assim, o fato de autistas tenderem a evitar estímulos auditivos desagradáveis limita, possivelmente, o aprendizado oriundo do contato externo. Outros estudos psicofísicos indicam, por meio de uma pequena amostra de crianças autistas, que os limiares de sensibilidade tátil se correlacionam com a reaçáo comportamental, emocional e social ${ }^{38}$.
$\mathrm{O}$ aspecto neurológico que relaciona a sinestesia ao autismo é a evidência para uma alteração do funcionamento perceptual ${ }^{16}$. Os indivíduos com TEA apresentam uma percepçáo intensificada para informaçôes procedentes de áreas cerebrais primárias e, ao mesmo tempo, uma redução da influência do processamento superior - o que se associa com um aumento na atividade em áreas cerebrais que processam informaçôes de baixo nível e uma maior autonomia destas ${ }^{16,21}$. Esse modelo sugere que as mudanças na organização e nos padrôes de ativação do cérebro estão diretamente relacionadas às diferenças cognitivas em autistas ${ }^{16}$. Na sinestesia, para um sistema específico, há também a intensificação da percepção, além de uma hiperconectividade entre as áreas sensoriais do cérebro ${ }^{16,41}$. Nota-se que uma percepção ampliada para cor acontece em sinestetas que possuem a alteração no sistema visual, assim como aqueles que possuem uma sinestesia relacionada ao tato têm a percepção melhorada nesse aspecto ${ }^{41}$.

As mudanças na percepção sensorial são correlacionadas com as conexốes neuronais alteradas em indivíduos autistas e sinestetas ${ }^{16}$. Estudos de neuroimagem confirmam que tanto a sinestesia quanto o autismo estáo associados a diferenças estruturais e funcionais no cérebro. Uma das hipóteses da sinestesia indica que há uma hiperconectividade neuronal entre diferentes regiōes cerebrais, assim como uma das hipóteses do autismo implica a redução das conexôes neurais de longo alcance e, em paralelo, um aumento das conexóes locais de curto alcance. Ambos os fenômenos podem ser pertinentes a uma falha ou alteração na poda sináptica ${ }^{9,18}$. Sendo assim, o aumento da conectividade local pode se relacionar a alteraçōes sensoriais tanto no autismo quanto na sinestesia ${ }^{18,37}$. Nesse caso, o modelo da ativação cruzada que ocorre em virtude da falha na poda sináptica explica a comunicação aumentada entre locais adjacentes do cérebro envolvidos com o processamento de estímulos indutores e concorrentes ${ }^{16}$. Ainda, a diferença no funcionamento perceptual dos indivíduos com TEA pode ser decorrente de um déficit para filtrar ou processar de forma correta informações advindas de distintas áreas sensoriais - no autismo há um desempenho abaixo do padrão em condições que exigem o colapso de diferentes informaçōes ${ }^{38}$.

Além dos aspectos referidos existem evidências genéticas para a ligação entre o TEA e a sinestesia, já que ambos podem estar relacionados a um conjunto de alteraçôes nesse aspecto. A hiperconectividade entre as áreas cerebrais, que causa alteraçóes sensoriais tanto no autismo quanto na sinestesia, pode ser explicada pela mutação de genes específicos para o desenvolvimento de conexóes estruturais e funcionais ${ }^{16}$. Uma correlação possível dá-se em relação ao cromossomo $\mathrm{X}$, pois tanto a sinestesia quanto o autismo podem, em hipótese, estar atrelados a ele; a sinestesia quando se relaciona à 
transmissão genética e o autismo à mutação e a comorbidades associadas a este cromossomo ${ }^{15,29,35}$.

Outra evidência foi percebida em um recente mapeamento genético, que investigou 43 famílias com sinestesia visual-auditiva, sendo encontrada uma significativa relação entre a sinestesia e o autismo; especificamente o cromossomo 2 está implicado tanto na sinestesia quanto no autismo ${ }^{7,37}$.

O receptor NMDA, que desempenha uma participação importante para a plasticidade cerebral e nos processos de memorização e aprendizado, também parece estar implicado tanto no autismo quanto na sinestesia. Ademais, alteraçôes do gene Reelin (RELN) pode também relacionar a sinestesia ao TEA, o que constitui um forte candidato para o entendimento das alteraçôes em ambos. O RELN exerce um papel importante para o desenvolvimento do córtex cerebral e sua organizaçãoo ${ }^{7,36}$.

\section{Conclusão}

A sinestesia e o TEA podem apresentar, fundamentalmente, uma correlação. Tal ligação deve-se aos fatores significantes encontrados na literatura, como o aumento da prevalência da sinestesia em indivíduos autistas, bem como alteraçóes genéticas e mecanismos neuronais semelhantes. Ainda, nas alteraçóes neurais, outro ponto em que as condiçóes convergem é no processamento perceptual sensorial alterado. Com base nisso, pode-se pensar tanto no TEA quanto na sinestesia como um transtorno e uma condição que possuem, essencialmente, uma natureza de aspecto sensorial.

As diferenças comportamentais e sensoriais em indivíduos autistas e sinestetas apresentam-se como um desafio para futuras pesquisas compreenderem melhor os fundamentos neurais do processamento sensorial básico em ambos. A interpretação da neurociência ainda é prematura, em decorrência da heterogeneidade das desordens e pela dificuldade em achar meios precisos que encontrem uma relação, em nível neuronal, entre a sinestesia e o TEA.

\section{Referências}

1. Simner J, Mulvenna C, Sagiv N, Tsakanikos E, Witherby SA, Fraser C, et al. Synesthesia: the prevalence of atypical cross-modal experiences. Perception.2006;35(8):1024-33.

2. Ramachandran VS, Hubbard EM. Neurocognitive mechanisms of synesthesia. Neuron. 2005;48(3):509-20.

3. Guimarães B. Todos os sentidos. Superinteressante. 2003; 185:45-8.

4. Hubbard E. Neurophysiology of synesthesia. Curr Psychiatry Rep. 2007;9(3):193-9.
5. Rouw R, van Driel J, Knip K, Ridderinkhof KR. Executive functions in synesthesia. Conscious Cogn. 2013;22(1):184-202.

6. Day SA. Some demographic and socio-cultural aspects of synesthesia. In: Robertson LC, Sagiv N, editors. Synesthesia: perspectives from cognitive neuroscience. Oxford University Press; 2005.

7. Asher JE, Lamb JA, Brocklebank D, Cazier J-B, Maestrini E, Addis L, et al. A whole-genome scan and fine-mapping linkage study of auditory-visual synesthesia reveals evidence of linkage to Chromosomes 2q24, 5q33,6p12, and 12p12. Am J Hum Genet. 2009;84(2):279-85.

8. Ramachandran VS, Hubbard EM. Ouvindo cores e degustando formas. Sci Am Brasil. 2003;2:48-55.

9. Bragança GF, Fonseca GM, Caramelli P. Synesthesia and music perception. Dement Neuropsychol. 2015;9(1):16-23.

10. Ramachandran VS, Hubbard EM. Psychophysical investigations into the neural basis of synesthesia. Proc Biol Sci.2001;268(1470):979-83.

11. Hubbard EM, Brang D, Ramachandran V. The cross-activation theory at 10. J Neuropsycol. 2011;5(2):152-77.

12. Maurer D, Spector F. Synesthesia: a new approach to understanding the development of perception. Dev Psychol. 2009;45(1):175-89.pheno

13. Cytowic RE. Touching tastes, seeing smells and shaking up brain science. New York: The Dana Fundation; 2002.

14. American Psychiatric Association. Manual diagnóstico e estatístico dos transtornos mentais (DSM-5). Porto Alegre: Artmed; 2014.

15. Cytowic RE. Synesthesia: phenomenology and neuropsychology. Psyche. 1995;2(10).

16. Neufeld J. Is synesthesia more common in patients with Asperger syndrome? Front Hum Neurosci. 2013;7:847.

17. Caminha RC, Lampreia C. Autismo: um transtorno de natureza sensorial? [dissertação]. Rio de Janeiro (RJ): Pontifícia Universidade Católica; 2008.

18. Belmonte MK, Allen G, Beckel-Mitchener A, Boulanger LM, Carper RA, Webb SJ. Autism and abnormal development of Brain connectivity. J Neurosci. 2004;24(42):9228-31.

19. Simmons D. Vision research: Vision in autism spectrum disorders. Elsevier. 2009;49(22):2705-39.

20. Mulvenna CM, Walsh V. Synesthesia: supernormal integration? Trends Cogn Sci.2006;10(8):350-2.

21. Casanova M, Trippe J. Radial cytoarchitecture and patterns of cortical connectivity in autism. Philos Trans R Soc London B Biol Sci. 2009;364(1522):1433-6.

22. Heer J. A review of synesthesia [Internet]. 2000 [citado em 2018 mar 15]. Disponível em: https://goo.gl/iubWYq

23. Baron-Cohen S, Burt L, Smith-Laittan F, Harrison J, Bolton P. Synaesthesia: prevalence and familiality. Perception. 1996;25(9):1073-80.

24. Grossenbacher PG, Lovelace CT. Mechanisms of synesthesia: cognitive and physiological constraints. Trends Cogn Sci. 2001;5(1):36-41. 
25. Barnett KJ, Finucane C, Asher JE, Bargary G, Corvin AP, Newell FN, et al. Familial patterns and the origins of individual differences in synaesthesia. Cognition. 2008;106(2):871-93.

26. Gregersen PK, Kowalsky E, Lee A, Baron-Cohen S, Fisher SE, Asher JE, et al. Absolute pitch exhibits phenotypic and genetic overlap with synesthesia. Hum Mol Genet.2013;22(10):2097-104.

27. Ward J, Simner J. Is synaesthesia an X-linked trait with lethality in males? Perception.2005;34(5):611-23.

28. Garcia PM. Principais causas neurológicas do autismo. Anais do $8^{\circ}$ Seminário de Pesquisa em Artes da Faculdade de Artes do Paraná; 2012; Curitiba: FAP; 2012. p. 256-9.

29. Carvalheira G, Vergani N, Brunoni D. Genética do autismo. Rev Bras Psiquiatr 2004;26(4):270-2.

30. Annunciato NF. Estruturas nervosas comprometidas no autismo: um enfoque neurogenético. Infanto - Rev Neuropsiq Inf Adol. 1995;3(3):38-52.

31. Moura PJ, Sato F, Mercadante MT. Bases neurobiológicas do autismo: enfoque no domínio da sociabilidade. Caderno de Pós-Graduação em Distúrbios do Desenvolvimento. 2005;5(1):47-57.

32. Garcia PM, Mosqueira CFF. Causas neurológicas do autismo. O Mosaico. 2011;(5):106-22.

33. Dalgalarrondo P. Evoluçáo do cérebro: sistema nervoso, psicologia e psicopatologia sob a perspectiva evolucionista. Porto Alegre: Artmed; 2011.
34. Herculano-Houzel S. O cérebro em transformação. Rio de Janeiro: Objetiva; 2005.

35. Coutinho JVSC, Bosso RMV. Autismo e genética: uma revisão de literatura. Revista Científica do ITPAC. 2015;8(1):1-14.

36. International Molecular Genetic Study of Autism Consortium. A genomewide screen for autism: strong evidence for linkage to chromosomes $2 \mathrm{q}, 7 \mathrm{q}$ and 16p. Am J Hum Genet. 2001;69(3):570-81.

37. Baron-Cohen S, Johnson D, Asher J, Wheelwright S, Fisher $\mathrm{SE}$, Gregersen PK, et al. Is synaesthesia more common in autism? Molecular Autism. 2013;4:40.

38. Marco EJ, Hinkley LB, Hill SS, Nagarajan SS. Sensory processing in autism: a review of neurophysiologic findings. Pediatr Res. 2011;69(5 Pt 2):48R-54R.

39. Klintwall L, Holm A, Eriksson M, Carlsson LH, Olsson MB, Hedvall A, et al. Sensory abnormalities in autism. A brief report. Res Dev Disabil. 2011;32(2):795-800.

40. Bouvet L, Donnadieu S, Valdois S, Caron C, Dawson M, Mottron L. Veridical mapping in savant ablilities, absolute pitch, and synesthesia: an autism case study. Front Psychol.2014;5:106.

41. Mottron L, Bouvet L, Bonnel A, Samson F, Burack JA, Dawson $\mathrm{M}$, et al. Veridical mapping in the development of exceptional autistic abilities. Neurosci Biobehav Rev. 2013;37(2):209-28.

\section{Como citar este artigo:}

Tomasi MC, Lopes J, Brandes JM, Klostermann HS, Cyrino LAR. Sinestesia e o transtorno do espectro do autismo (TEA). Rev. Aten. Saúde. 2018;16(55):81-88. 